\title{
Knowledge, Attitude \& Practice among psoriasis patients in India towards teledermatology during COVID-19 Pandemic.
}

\author{
Archana Mavoori $^{1 *}$, Sudhabala ${ }^{2}$, Rajiv Kumar Bandaru ${ }^{3}$ and Aruna Kumari Yerra ${ }^{4}$ \\ ${ }^{1}$ Assistant Professor, Department of Dermatology, Venereology \& Leprosy, Member of Telemedicine committee. ESIC Medical College \& Hospital, \\ Sanathnagar, Hyderabad, India. \\ ${ }^{2}$ Assistant Professor, Department of Preventive \& Social Medicine, Member of Telemedicine committee. ESIC Medical College \& Hospital, \\ Sanathanagar, Hyderabad, India. \\ ${ }^{3}$ Assistant Professor, Department of General Medicine, Member of Telemedicine committee. ESIC Medical College \& Hospital, Sanathnagar, \\ Hyderabad, India \\ ${ }^{4}$ Assistant Professor, Departmemt of Obstetrics \& Gynecology, Member of Telemedicine committee. ESIC Medical College \& Hospital, Sanathnagar, \\ Hyderabad, India
}

*Corresponding Author: Archana Mavoori, Assistant Professor, Department of Dermatology, Venereology \& Leprosy, Member of Telemedicine committee. ESIC Medical College \& Hospital, Sanathnagar, Hyderabad, India.

Received date: September 29, 2021; Accepted date: October 08, 2021; Published date: October 13, 2021

Citation: A Mavoori, Sudhabala, Rajiv K Bandaru, Aruna K Yerra. (2021) Knowledge, Attitude \& Practice among psoriasis patients in India towards teledermatology during COVID-19 Pandemic.J. Dermatology and Dermatitis. 6(4); Doi: 10.31579/2578-8949/088

Copyright: @2021 Archana Mavoori, This is an open-acscess article distributed under the terms of The Creative Commons. Attribution License, which permits unrestricted use, distribution, and reproduction in any medium, provided the original author and source are credited.

\begin{abstract}
:
Background: The current COVID-19 pandemic has imposed upon the entire community norms of social distancing and home quarantine. Follow up consultations in these times can be made through teledermatology through smart phones. Success of this technology in these hours of crisis depends upon the knowledge, attitude and behaviour of patients towards teledermatology. Follow up consultations done through teleconsultations will decrease risk of exposure to COVID-19 among psoriasis patients who need frequent follow ups.
\end{abstract}

Aim: The main objective of this study is to assess the awareness, knowledge, attitude and practice of teledermatology through teledermatology among psoriasis patients at a tertiary care teaching hospital.

Materials and Methods: A cross-sectional survey, from Psoriasis Clinic registry maintained in the outpatient department of DVL of a tertiary care teaching hospital in India is conducted. A pre-validated self-administered questionnaire is used for the survey to assess knowledge, attitude and practice of teledermatology. Analysis will be done as per study objectives using descriptive statistics for quantitative data and content analysis for qualitative data.

Results: Out of 150 patients, 87(58\%) were males and females were 63(42\%). Most common age group to participate in the study was 36-45 years- 43(28.7\%). Majority of participants were educated up to -graduate 53(35.3\%). Males had higher knowledge and attitude scores compared to females. Most of the patients found using teleconsutations easy and convenient.

Conclusion: Teledermatology is the need of the hour to be implemented in these hours of COVID-19 pandemic.

Key Words: teledermatology; psoriasis; COVID-19

\section{Introduction:}

A novel coronavirus named severe acute respiratory syndrome coronavirus 2 (SARS-CoV-2) was reported causing the disease known as COVID-19 in December 2019. As of June $19^{\text {th }}, 2020$, there have been 195 countries affected with 8.24 million cases and 446,000 deaths [1]. In India, every state has been affected and as of June $18^{\text {th }}$ there were 381,000 cases with 12907 deaths [1]. A significant rise in case numbers is expected in the coming weeks.

The Ministry of Health and Family Welfare (MoHFW) of India suggested implementation of several changes to curb spread of the corona virus [2]. Lockdown measures are considered the main factor in a decline in transmission from a median daily reproduction rate of 2.66 to 1.05 within 
a week [3]. Clinics, private hospitals are closed, OPDs are shut down and reduced to emergency cases, temperatures recorded on entry, wearing masks and having travel histories recorded and telemedicine is being implemented. Doctors are mandated to wear full PPE [4]. Due to the unprecedented nature of this pandemic there is uncertainty among dermatologists regarding the precautions to be taken during consultations.

During these hours of crisis, telemedicine is a boon which can be used by practitioners for consultations. It reduces risk of acquiring novel corona virus, reduces travelling during lockdown times and makes healthcare easily accessible. The WHO definition of Telemedicine is as 'The delivery of health care services, where distance is a critical factor, by all health care professionals using information and communication technologies for the exchange of valid information for diagnosis, treatment and prevention of disease and injuries, research and evaluation, and for the continuing education of health care providers, all in the interests of advancing the health of individuals and their communities [5]. The term is an umbrella term that includes tele-health, electronic medical records, e-health and other components of health information technology [6]. It is seen as a potential means of overcoming the growing shortage of health practitioners in developing countries [7]. There are 3 primary modes: Video, Audio, or Text (chat, messaging, email, fax etc.) Each one of these technology systems has their respective strengths, weaknesses, and contexts, in which, they may be appropriate or inadequate to deliver a proper diagnosis [5]. An android app that can deliver both real time video consultation RT-TD (through video and/or audio chat) and asynchronous store and forward SAF (patient can send the picture and/or text, and the dermatologist can reply at a convenient time). Successful implementation of any new technology depends on factors like the knowledge of the concept, attitude and practical implementation by the concerned professionals. In these times of COVID-19 and the need for social distancing, not many patients are familiar with tele dermatology and this can serve as an interface between patients and dermatologists.

Psoriasis is an immune mediated genetically determined chronic dermatological disorder which affects skin, nails, joints and has various systemic associations. There is evidence that the disease is associated with a high impact on the health-related quality of life and considerable cost. In India, incidence of psoriasis was found to be ranged between $0.44 \%$ $2.3 \%[8-10]$.

Patients with psoriasis need constant follow up. Especially those on systemic treatment with drugs such as methotrexate, cyclosporine, acitretin etc or those on biologics need regular check-ups and regular monitoring of few biochemical parameters. The current COVID-19 pandemic has imposed upon the entire community norms of social distancing and home quarantine. Follow up consultations in these times can be made through Tele dermatology. Success of this technology in these hours of crisis depends upon the knowledge, attitude and behaviour of patients towards teledermatology.

\section{Materials \& methods:}

Study design \& sites: The study is a questionnaire based cross sectional analysis. 150 patients diagnosed with psoriasis, recruited from the outpatient department of dermatology, venereology \& leprosy of a tertiary care hospital at Hyderabad, India were included in the study. The sample included patients with psoriasis diagnosed clinically, histopathologically or by both means seeking treatment in the outpatient department with at least one year since initial diagnosis. Those not willing to participate in the study, those unable to answer the questionnaire were excluded from the study.

Questionnaire Design: A pre-tested structured, trilingual questionnaire was developed to investigate key research questions comprised of both open- and close-ended questions. The questionnaire was divided into 6 main categories including demographic information, socio economic information, general knowledge about COVID-19, questions about knowledge, questions about attitude and questions about practice. To assess knowledge, attitude \& practice 5 questions in each section were asked. Cut of $>=3$ was taken as good knowledge. Consent was taken from each patient in google forms and institutional ethical committee clearance was also obtained.

KAP Score: To calculate KAP a scoring system was prepared. Each correct answer was coded as 1 while each incorrect answer was coded as 0 . In practice session, components with better practice obtained a higher score upto 5 while respondents with poorer practice received lower scores. The final score for each category was then divided in quartiles. Four categories of knowledge, attitude and practice were outlined according to the score obtained by each respondent. Good knowledge and good practices cut off was $>=3$ for maximum score of 5 ; attitude was marked on Likert scale 1-5 with total score of 25 where cut off of $>=12$ was taken as positive attitude. The Cronbach's alpha test value was found to be 0.603 with mean inter item correlation value of 0.171 for this KAP scale on reliability analysis.

\section{Statistical analysis:}

The collected data was entered in the statistics package for social science (SPSS) version 22 for Windows. All continuous data were expressed as mean (_SD), and categorical variables were expressed as numbers and percentages. Descriptive statistics and frequency distributions were used describe participant characteristics. For variables with greater than two categories, one-way analysis of variance ANOVA was used to compare means. To reconfirm the predictor variables- Binary logistic regression analysis was used to measure various outcomes such as knowledge about COVID-19, Telemedicine, their practices and attitudes.

\section{Results:}

A total of 150 patients were included in the study. Out of them, 87(58\%) were males and females were 63(42\%). Most common age group to participate in the study was 36-45 years- $43(28.7 \%$ ) followed by $46-55$ years- $36(24 \%)$. Majority of participants were educated upto -graduate level $53(35.3 \%)$. The mean duration of psoriasis was $7.43+5.46$ years. $83(55.3 \%)$ patients had comorbidities like Diabetes mellitus, obesity, hypertension and hyperlipidaemia. 


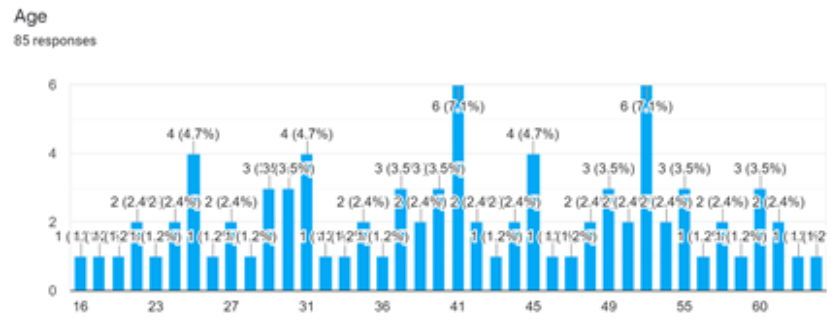

For how many years have you been suffering from psoriasis? 85 responses

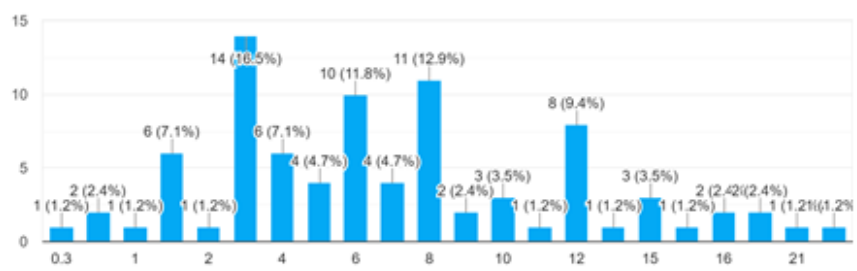

1) Are you worried about getting the Corona Virus? 85 responses

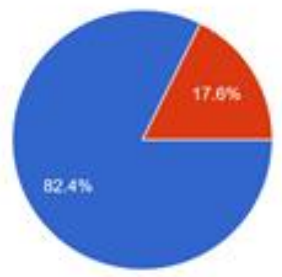

3) Do you think the lockdown is useful in preventing spread of Corona virus? 85 responses
Education level

85 responses

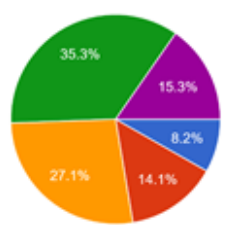

- uneducated

- Primary schood

- graturate

- post graduate

Do you have any comorbidities ( High BP, diabetes, obesity, High cholesterol) that need regular follow up visits to the hospital?

85 responses

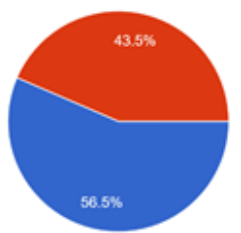

Y Yos

2) Are you maintaining social distancing and hand hygeine? 85 responses

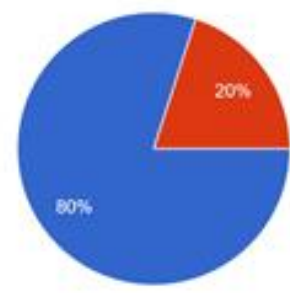

- Yes

- No

4) Do you think most of the patients with Corona virus have mild symptoms? 85 responses

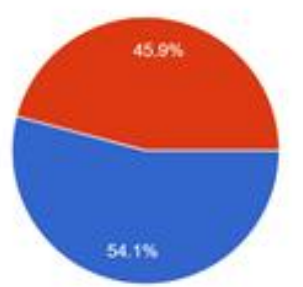

- Yes

- No

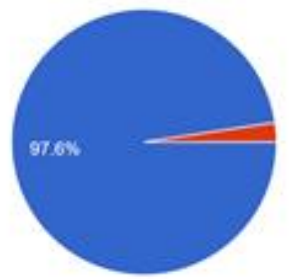

- Yes

- No 
5) Do you think the course of COVID-19 could be devastating? 85 responses

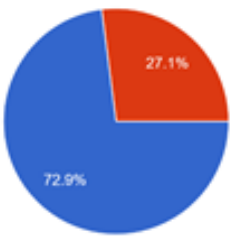

2) Are you aware about course of the psoriasis? 85 responses

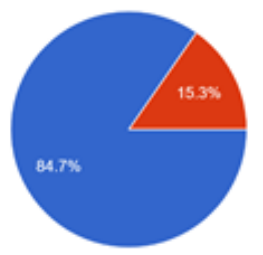

Y Yos
1) Are you aware about Teledermatology? 85 responses

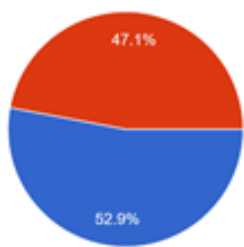

3) Are you regularly using the medications even though you cannot come for follow up because of lockdown

s5 responses

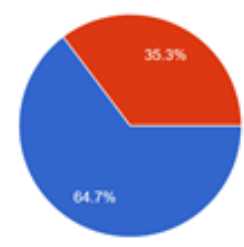

Yes
Y No
4) Do you think Pscriasis worsens/ relapses if you do not come for regular follow up visits? as rempososes

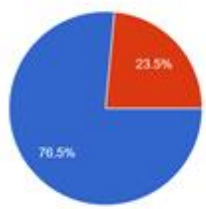

Nos

1) You are entirely responsible for taking proper skin care while suffering from Psoriasis. ins tesponses

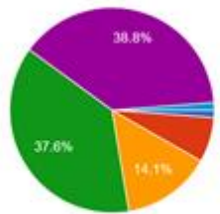

- Srongly diangee

Nectral

- Moderately agee

- srongly agree
5) Do you think teledermatology consultations for follow up during COVID crisis are useful? 85 responses

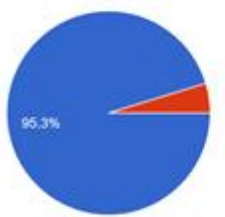

YNo
2) Comorbidities ( high BP. Diabetes, Obesity etc) will worsen the psoriasis prognosis. 85 cesponses

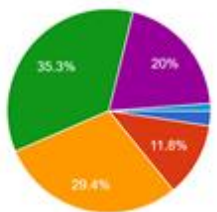

- Stronol doagree

- Moderatey Oisagre

- Modemely Agre

- Strongy Agree 
3) The COVD crisis and social distancing influenced your family members / friends behaviour towards you. istespenses
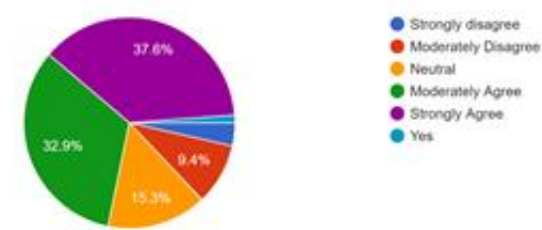

5) You are satisfled if the doctor does not examine you personally. as responses
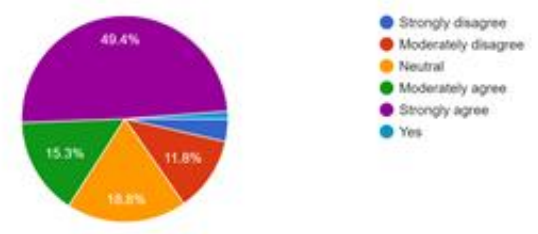

2) Do you take prescribed medicines/ apply creams, lotions regularly? es responses

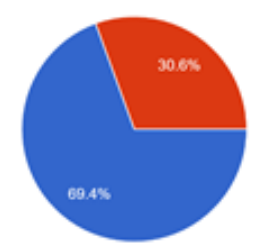

$$
\text { - Yos }
$$

4) Do you think tele consultations save your time? 85 responses
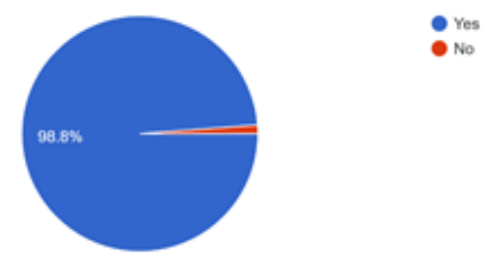

Knowledge about COVID-19 Score: The maximum knowledge score was 5. The mean score was 3.88 and standard deviation (SD) was 0.810 . The study indicated that $103(68.7 \%)$ of participants had good knowledge regarding COVID-19. About 79.9\% ( $\mathrm{n}=119)$ of participants were worried about acquiring the corona virus. $120(80.5 \%)$ were maintain social distance and hand hygiene. 145(97.3\%) think that the lockdown is useful in preventing the spread of corona virus. $80(53.7 \%)$ - think that most of patients with COVID-19 will have mild symptoms and $111(74.5 \%)$ think that the course of COVID-19 could be devastating. The study indicates that males $69(67 \%)$ had higher knowledge than females $34(33 \%)$. The patients in 36-45 years of age group had better knowledge
4) Tele consultation is better than direct consultation in COVD crisis. is responses

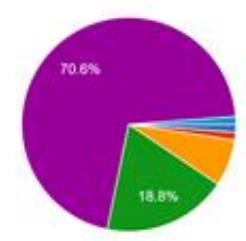

- svocoly disgoree - Moderately Disagees - Neviral - Moderately Apres - Storgly Agree

1) Do you frequently come for follow up visits to the hospital? 85 responses

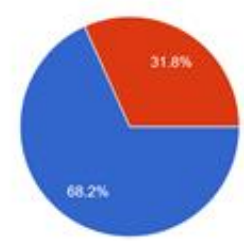

- Nos

3) Did you find using the teleconsutation app easy?

85 responses

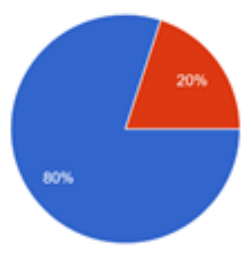

- Yos

5) Does the teleconsultation decrease your chances of exposure to Corona virus? 85 responses

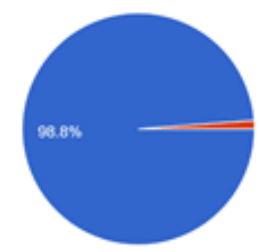

- Yes

31(30\%). Patients educated up to graduate level 39 (37.9\%) had better knowledge compared to others.

Knowledge about Tele dermatology score: The maximum score in this category was 5. 76(51\%) of patients were aware about tele dermatology. 124(83.2\%) of patients were aware about the course of psoriasis. 96(64.4\%) of patients reveal that they have been regularly using medications during lockdown even though they cannot come for regular follow up visits. $116(77.9 \%)$ of patients think that the course of psoriasis will worsen if they do not come for regular follow up visits. 141(94.6\%) of patients think that tele dermatology consultations are useful for follow up visits during COVID-19 crisis. Figure 1. 


\section{knowledge about teledermatology}

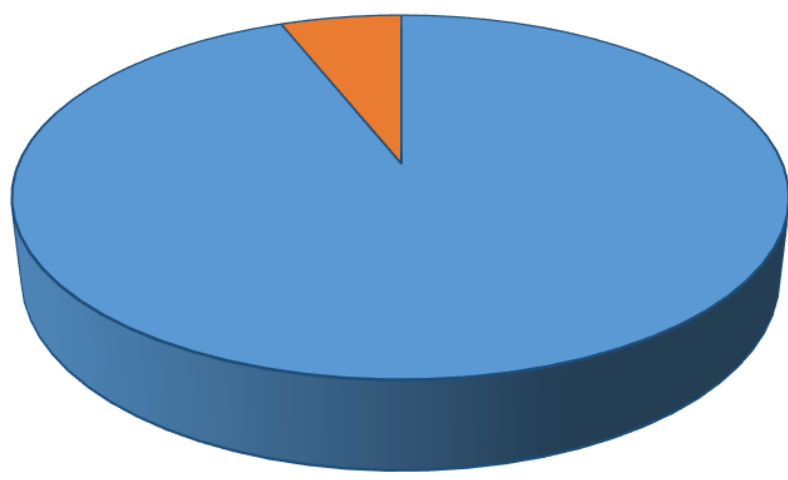

Found useful in COVID-19 times

DFound not useful

\section{Figure 1}

Males had higher knowledge 67(67.7\%) about tele dermatology and its benefits during COVID-19 crisis. 36-45 years of age group 27(27.3\%) of patients had better knowledge in comparison to other groups. Graduate level of educated patients had good knowledge 42(42.4\%) about COVID19 and advantages of tele dermatology during lockdown period.

Attitude Score: The maximum score was 25 for 5 questions on attitude. $60(40.3 \%)$ of patients took the entire responsibility of psoriasis skin care upon themselves. 51(34.2\%) of patients moderately agreed and $47(31.5 \%)$ were neutral that their comorbidities will worsen the course of psoriasis. $55(36.9 \%)$ of patients strongly agreed and 49(32.9\%) moderately agreed that the influence of family and friend's behaviour towards them was influenced by COVID-19 crisis and social distancing. Almost 99(66.4\%) strongly agreed that tele consultation is better than direct consultation during the COVID-19 crisis. Strongly agreed were $67(45 \%)$ and $31(20.8 \%)$ were neutral and $25(16.8 \%)$ moderately agreed that they were satisfied if the doctor does not examine them personally. It can be noted that 36-45 years of age group and male gender is associated with positive attitude.

Practice score: The maximum practice score was 5. 102(68\%) of psoriasis patients reported that they would frequently come for follow up visits, $105(70 \%)$ took prescribed medicines, applied creams, lotions regularly. 117(78\%) found using the tele consultation app easy. $148(98.7 \%)$ reported tele consultations saved their time, avoiding travelling. And 148(98.7\%) reported decreasing chances of risk of exposure to corona virus due to tele consultations. Figure 2. On one-way ANOVA we found statistically significant association of sex and education with knowledge related to COVID-19, knowledge about tele dermatology, their practices and attitude where males had higher mean score and as education increased the score also increased. Table 1 and Table 2. Attitude mean scores were found to be insignificant. This was reconfirmed with binary logistic regression analysis using Enter method. Table 3

\section{Practice score}

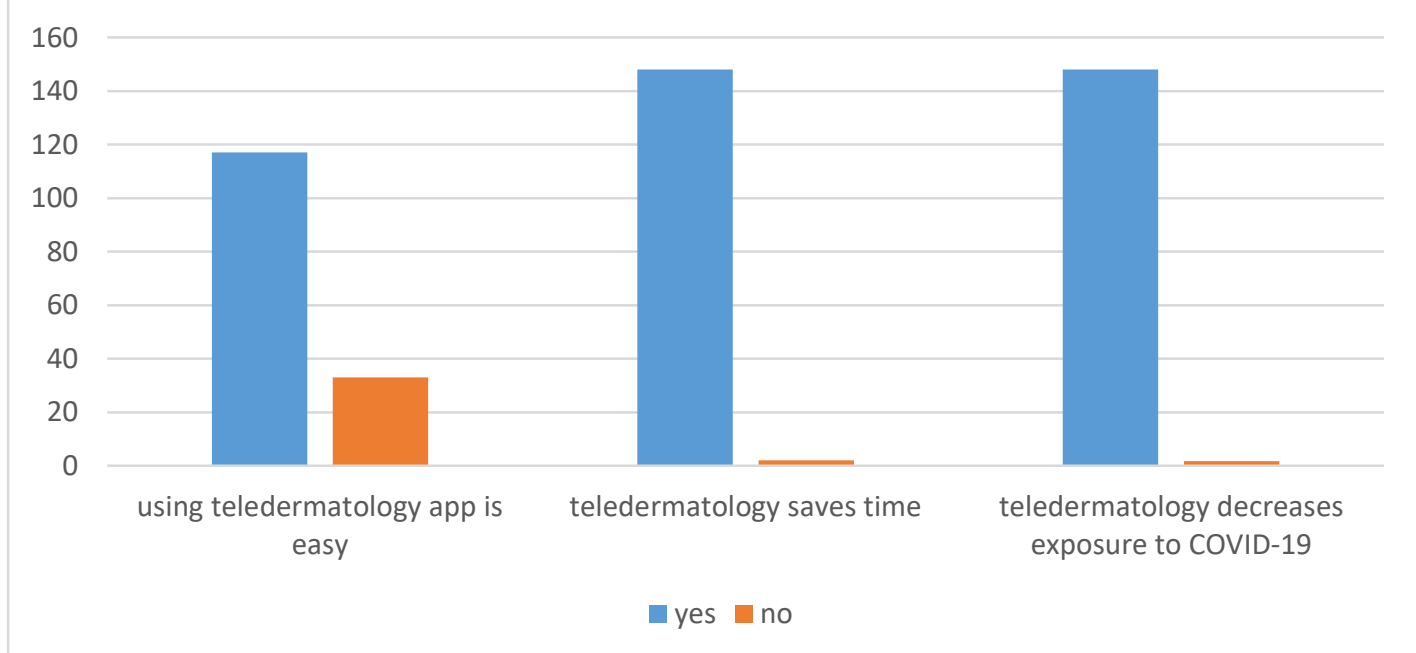

Figure 2: Practice score

\begin{tabular}{|l|l|l|}
\hline Sex & Mean scores of knowledge about COVID-19 & p-value \\
\hline Male & $4.03+0.798$ & \\
\hline
\end{tabular}




\begin{tabular}{|l|l|l|}
\hline female & $3.66+0.782$ & 0.006 \\
\hline & $\begin{array}{l}\text { Mean scores of knowledge about tele } \\
\text { dermatology }\end{array}$ & \\
\hline $\begin{array}{l}\text { Male } \\
\text { female }\end{array}$ & $\begin{array}{l}3.89+0.928 \\
3.46+1.059\end{array}$ & 0.008 \\
\hline & Mean scores of attitude & \\
\hline $\begin{array}{l}\text { Male } \\
\text { female }\end{array}$ & $\begin{array}{l}20.22+2.438 \\
19.30+3.082\end{array}$ & 0.041 \\
\hline & Mean scores of practice & \\
\hline $\begin{array}{l}\text { Male } \\
\text { female }\end{array}$ & $\begin{array}{l}4.52+0.775 \\
3.58+1.252\end{array}$ & 0.0001 \\
\hline
\end{tabular}

Table 1: One-way ANOVA between knowledge, attitude, and practices with sex

\begin{tabular}{|l|l|l|}
\hline Education & Mean scores of knowledge about COVID-19 & p-value \\
\hline Uneducated & $3.84+0.898$ & \\
Primary & $3.40+0.502$ & \\
High school & $3.90+0.632$ & \\
Graduate & $3.94+0.969$ & \\
Post graduate & $4.12+0.740$ & \\
\hline & Mean scores of knowledge about tele & \\
\hline Uneducated & dermatology & \\
Primary & $3.38+0.767$ & \\
High school & $3.30+0.571$ & 0.026 \\
Graduate & $3.60+1.007$ & \\
Post graduate & $3.83+1.13$ & \\
\hline & $4.16+0.91$ & \\
\hline Uneducated & Mean scores of practices & \\
Primary & $3.61+1.19$ & \\
High school & $2.75+0.91$ & \\
Graduate & $3.95+1.06$ & \\
Post graduate & $4.62+0.76$ & \\
\hline
\end{tabular}

Table 2: One way ANOVA between knowledge, attitude and practices with education

\begin{tabular}{|l|l|l|l|}
\hline Variables & Outcome & Odds ratio & p-value \\
\hline $\begin{array}{l}\text { Educational } \\
\text { level }\end{array}$ & $\begin{array}{l}\text { Knowledge about } \\
\text { telemedicine }\end{array}$ & 1.939 & 0.002 \\
\hline Sex & $\begin{array}{l}\text { Knowledge about } \\
\text { COVID-19 }\end{array}$ & 0.411 & 0.039 \\
\hline $\begin{array}{l}\text { Educational } \\
\text { level } \\
\text { Sex }\end{array}$ & $\begin{array}{l}\text { Practices regarding } \\
\text { tele dermatology }\end{array}$ & 0.275 & 0.0001 \\
\hline
\end{tabular}

Table 3: Binary logistic regression analysis predicting the socio demographic variables with various outcomes

\section{Discussion:}

No study was found assessing the Knowledge, Attitude and Practices (KAP) of teledermatology among psoriasis patients during COVID-19 crisis. Thus, it was difficult to compare the current results with others.

The results showed that participants with better knowledge also had a better attitude score. In the practice section, $78 \%$ found using the app easy. Inadequate knowledge regarding spread of corona virus tends to decrease awareness and may lead to poor practices leading to increased risk of acquiring the virus. Good knowledge about teledermatology, and better attitude decreases chances of patients' risk of exposure to corona virus.

It was found that males are more knowledgeable about teleconsultations than females. Subgroup analysis revealed that age and educational level were significantly associated $(\mathrm{p}<0.05)$ with knowledge and experience with teleconsultations. In the current study it is noted that knowledge and attitude improved with age. Respondents with a lower age or with a higher educational level had more often heard of the term tele dermatology or its applications and were more likely to have experience with online apps. Similar results were observed in a study on Knowledge, use and attitude 
towards eHealth among patients with chronic lung diseases by Hofstede et al [11].

Good knowledge of COVID-19 was significant among psoriasis patients, who had higher socioeconomic status. This finding was consistent with study by Hofstede et al [11]. This could be explained by the fact that participants with higher socioeconomic status have better access to education and alternative private check-ups without waiting for conservative treatment facilities in the health system. In the current study, controlling other variables, educational status had a significant association with good knowledge. This might be because educated participants are able to read necessary information easily compared to the illiterates.

Majority of patients had no previous experience with telemedicine. This finding is like a study conducted by Jayakody et al [12]. In the current study, duration of psoriasis was a significant predictor of practice. This may be due to regular counselling and contact with health professionals.

It was also observed that among female patients, follow up visits were not regular, treatment routine and self-care was poor. This could be because of elderly female patients' limited access to health care. Females were not maintaining social distancing and hand hygiene during lockdown. This could be because of overburden due to increase in work at home, pressure to meet demands of all family members who are at home due to lockdown.

The COVID-19 crisis and social distancing had further added to the stigma faced by psoriasis patients who are treated as untouchables by some family members.

Evidence suggests that regular follow up visits are a core part of the treatment of psoriasis [13]. Patient education is the most constructive track that could assist with early detection, lessen the complications, and assist with the management of psoriasis. This study reemphasized the fact that properly designed and implemented telemedicine apps would be fruitful for patients with psoriasis. Provided complete information on COVID-19 characteristics, healthcare professionals could effectively implement tele dermatology, according to the psoriasis patients' needs who need regular follow ups due to chronic course and frequent relapses. Proper implementation of lockdown measures and effective maintenance of social distancing and hand hygiene go a long way in preventing transmission of novel corona virus among patients.

\section{Conclusions:}

The COVID-19 pandemic proved that telemedicine and teledermatology which were just an option before are indeed essential in crisis times. As most of the patients do not have the facility of computers, laptops and internet to have teledermatology consultations, we are implementing teledermatology through a unique android app. As most of the patients have smart phones with $4 \mathrm{G} / 3 \mathrm{G}$ internet facilities, using tele consultations and follow up visits would be tested for simplicity and convenience. Widespread use of smartphones and android/iOS apps; ease of use; increased availability of health care professionals; reduced need for travelling; decreased exposure to the corona virus are all the advantages that make patients with chronic dermatological problems who require regular follow ups choose teledermatology as the preferred means of consultations. Widespread propaganda will help teledermatology penetrate deeper among society and will soon emerge as the most convenient means of consultations.

\section{Acknowledgments}

The authors are grateful to the Dean, and the entire telemedicine committee members for their guidance and cordial support. Special mention to all participants who took time during the covid-19 crisis and participated in this study with enthusiasm.

\section{References}

1. Kucharski AJ, Russel TW, Diamond C et al. (2020). Early dynamics of transmission and control of COVID-19: a mathematical modelling study. Lancet infect Dis.

2. Chen Y, Pradhan S, Xue S. (2020). What are we doing in the dermatology outpatient department amidst the raging of the 2019 novel coronavirus? J Am Acad Dermatol. 82(4): 1034.

3. Wootton R. (2001). Recent advances in telemedicine. [1] British Medical Journal. 323: 557-560.

4. WHO. (2010). Telemedicine Opportunities and Developments in Member States - Report [2] on the second global survey on eHealth Global Observatory for eHealth series. 2: 96.

5. Okhandiar RP, Banerjee BN. (1963). Psoriasis in the tropics: An epidemiological survey. J Indian Med Assoc. 41: 550-556.

6. Bedi TR. (1995). Clinical profile of psoriasis in North India. Indian J Dermatol Venereol Leprol. 61: 202-205.

7. Kaur I, Handa S, Kumar B. (1997). Natural history of psoriasis: a study from the Indian subcontinent. J Dermatol. 24: 230-234.

8. Hofstede J, Bie J de, Wijngaarden B van, Heijmans M. (2014). Knowledge, use and attitude towards eHealth among patients with chronic lung diseases. International Journal of Medical Informatics. 83(12): 967-974.

9. Jayakody, D H. (2019). A descriptive cross-sectional study: knowledge, attitude and practice on telemedicine for healthcare among the general public in the western province of Sri Lanka. Sri Lanka Journal of Bio-Medical Informatics. 10(3): 17.

10. Kim WB, Jerome D, Yeung J. (2017). Diagnosis, and management of psoriasis. Can Fam Physician. 63(4): 278-285.
This work is licensed under Creative Commons Attribution 4.0 License
Ready to submit your research? Choose Auctores and benefit from:

$>$ fast, convenient online submission

$>$ rigorous peer review by experienced research in your field

$>$ rapid publication on acceptance

$>$ authors retain copyrights

$>$ unique DOI for all articles

$>$ immediate, unrestricted online access

At Auctores, research is always in progress.

Learn more https://auctoresonline.org/journals/dermatology-anddermatitis 